\title{
Happy together: microbial communities that hook up to swap electrons
}

\author{
Derek R Lovley \\ Department of Microbiology, Morrill IV N Science Center, University of Massachusetts, Amherst, MA, USA
}

\begin{abstract}
The discovery of direct interspecies electron transfer (DIET) and cable bacteria has demonstrated that microbial cells can exchange electrons over long distances $(\mu \mathrm{m}-\mathrm{cm})$ through electrical connections. For example, in the presence of cable bacteria electrons are rapidly transported over centimeter distances, coupling the oxidation of reduced sulfur compounds in anoxic sediments to oxygen reduction in overlying surficial sediments. Bacteria and archaea wired for DIET are found in anaerobic methane-producing and methane-consuming communities. Electrical connections between gut microbes and host cells have also been proposed. Iterative environmental and defined culture studies on methanogenic communities revealed the importance of electrically conductive pili and c-type cytochromes in natural electrical grids, and demonstrated that conductive carbon materials and magnetite can substitute for these biological connectors to facilitate DIET. This understanding has led to strategies to enhance and stabilize anaerobic digestion. Key unknowns warranting further investigation include elucidation of the archaeal electrical connections facilitating DIET-based methane production and consumption; and the mechanisms for long-range electron transfer through cable bacteria. A better understanding of mechanisms for cell-to-cell electron transfer could facilitate the hunt for additional electrically connected microbial communities with omics approaches and could advance spin-off applications such as the development of sustainable bioelectronics materials and bioelectrochemical technologies.
\end{abstract}

The ISME Journal (2017) 11, 327-336; doi:10.1038/ismej.2016.136; published online 1 November 2016

\section{Introduction}

Cooperation is a hallmark of stable microbial communities. The best-known mechanism of interspecies exchange of nutrients, carbon substrates and information is through soluble molecules that are released into the extracellular environment and reach other cells via diffusion (Phelan et al., 2012; Ponomarova and Patil, 2015). Some microorganisms exchange electrons in a similar manner with soluble electron shuttles, such as $\mathrm{H}_{2}$ or formate, ferrying electrons between electron-donating and electronaccepting cells (Stams and Plugge, 2009; Sieber et al., 2012; Shrestha and Rotaru, 2014).

However, diffusion is a relatively slow and indirect mechanism to relay energy and information. Direct interspecies electron transfer (DIET) may be faster and more specific (Summers et al., 2010; Lovley, 2011). Electrical connections that support DIET include electrically conductive pili (e-pili) and cytochromes (Summers et al., 2010), minerals (Kato et al., 2012a) and abiotic carbon (Liu et al., 2012). Electrically connected microbial communities

Correspondence: DR Lovley, Department of Microbiology, Morrill IV N Science Center, University of Massachusetts, Amherst, MA 01003, USA. E-mail: dlovley@microbio.umass.edu

Received 11 April 2016; revised 29 August 2016; accepted 4 September 2016; published online 1 November 2016 (e-communities) recognized to date are primarily restricted to a few anaerobic environments in which bacteria and archaea electrically connect to either produce (Morita et al., 2011; Kato et al., 2012b; Rotaru et al., 2014b) or consume (McGlynn et al., 2015; Wegener et al., 2015) methane. Conductive channels through the anoxic-oxic zone of aquatic sediments also appear to be the result of long-range electrical connections between microbial cells (Pfeffer et al., 2012). A major challenge in identifying other e-communities has been a poor understanding of the types of electrical connections that may exist between cells. For example, although the e-pili of Geobacter species have been extensively studied, they are a recent evolutionary event and restricted to only a minority of the wide diversity microorganisms that are known to be capable of electrical communication with their extracellular environment (Holmes et al., 2016). As discussed below, other types of microbial electrical connectors seem possible. The proposed potential for electrical interactions between microbes and human cells (Ericsson et al., 2015) demonstrates the need to think broadly in the early stages of e-community research.

The purpose of this minireview is to describe the function of known e-communities, which may provide information that will aid the search for additional types of communities that function via DIET; and to describe how a developing 
understanding of e-communities is providing new insights into important biogeochemical cycles and the development of novel applications in bioenergy and biomaterials.

\section{Cable bacteria}

One of the most amazing phenomena in electromicrobiology are cable bacteria, which appear to facilitate long-range electron transport from reduced sulfidic zones to oxygen in a diversity of marine and freshwater sediments (Pfeffer et al., 2012; RissgaardPetersen et al., 2012; Larsen et al., 2014; Schauer et al., 2014; Malkin and Meysman, 2015; Nielsen and Risgaard-Petersen, 2015; Risgaard-Petersen et al., 2015). In some instances nitrate, rather than oxygen, may serve as the electron acceptor (Marzocchi et al., 2014). The cable bacteria, which are within the family Desulfobulbaceae, form chains, one cell in diameter, extending thousands of cells in length (Pfeffer et al., 2012). Growth of the cable bacteria is associated with an oxidation of sulfide minerals that is much faster than could be accounted for by diffusive processes, and an increase in $\mathrm{pH}$ in the oxic zone, consistent with the consumption of protons during oxygen reduction to water (Pfeffer et al., 2012; Rissgaard-Petersen et al., 2012). Cutting horizontally through the sediments with a thin tungsten wire eliminated the apparent electron transfer as did emplacement of filters with pore sizes too small to permit growth of the bacteria through the filter (Pfeffer et al., 2012). These and other controls ruled out the possibility of electron transport through conductive minerals, which can confer substantial conductivity in some reduced marine sediments (Malvankar et al., 2015a). The simplest explanation for these observations is that: (1) cable bacteria oxidize sulfide in the anoxic zone; (2) the electrons derived from sulfide are transported through the cable into the oxic zone; and (3) the cable bacteria in the oxic zone transfer the electrons to oxygen (Figure 1). However, it is important to recognize that these three proposed steps are not yet fully verified.

Distinct ridges of unknown composition run along the length of the filaments, which appear to share intercellular periplasmic connections. Electrostatic force microscopy indicated that the ridges have charge storage capacity (Pfeffer et al., 2012). However, the conductivity of these structures has not been measured. There was no measurable current between electrodes placed in contact with the outer cell surface, suggesting that the proposed electron transfer was internal and that the outer membrane served as an insulator (Pfeffer et al., 2012). Additional efforts to connect the cable bacteria with electrodes in a manner that would yield estimates of the conductivity along the length of the filaments have not been successful (Nielsen and RisgaardPetersen, 2015). Thus, it may be necessary to dissect

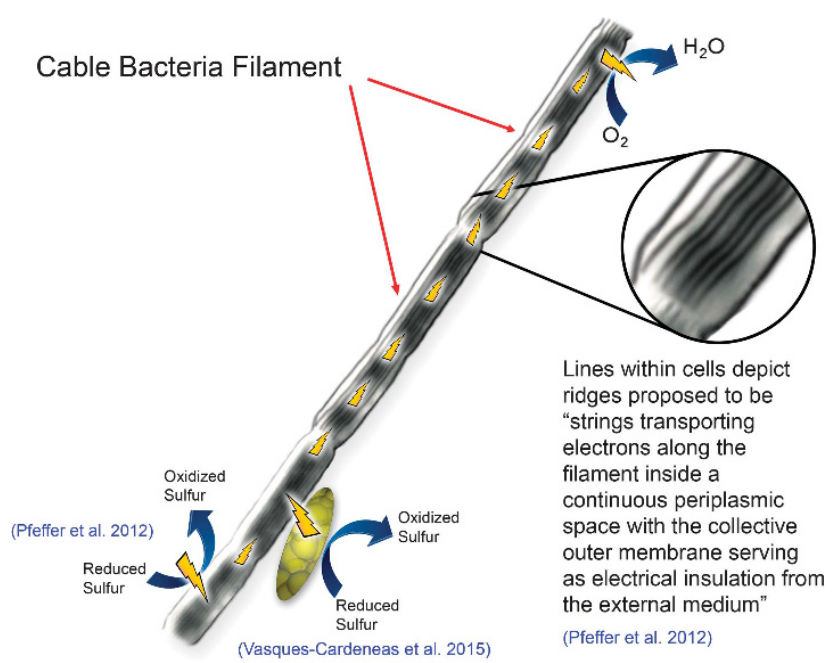

Figure 1 Model for long-range electron transport through the interior of cable bacteria with proposed reactions and relevant references. Lightning bolts depict the direction of electron flow.

the ridges from the cells in order to better evaluate the suggestion that they are electrically conductive.

Quantitative biogeochemical models will also require direct measurements of the contribution of cable bacteria to sediment conductivity because the indirect methods currently in use are probably underestimating electron fluxes from the sulfidic to oxic zones (Vasquez-Cardenas et al., 2015). Electrochemical studies of sediments containing cable bacteria have been reported (Risgaard-Petersen et al., 2014), but the methods employed did not measure the rate of electron transport through the sediment. Techniques for measuring sediment conductivity are available (Malvankar et al., 2015a) and it would be helpful in better understanding this process to directly compare the conductivity of sediments that contain cable bacteria with similar sediments in which cable bacteria are absent.

Cable bacteria may also be involved in DIET (Vasquez-Cardenas et al., 2015). ${ }^{13} \mathrm{C}$-labeling studies suggested that chemolithoautotrophic Epsilon- and Gammaproteobacteria are responsible for the sulfur oxidation that takes place in the presence of cable bacteria (Vasquez-Cardenas et al., 2015). It is hypothesized that the sulfur oxidizers transfer electrons to the Desulfobulbaceae filaments via DIET through as yet to be determined electrical connections (Vasquez-Cardenas et al., 2015). Further analysis with a broader range of labeling and omics tools, as have been employed for the study of other sulfuroxidizing marine populations (Dyksam et al., 2016), may help better define these interactions.

There is a clear need to develop strategies to culture cable bacteria in order to study in more detail the inferences that have been made about their conductivity, their mechanisms of long-range electron transport and potential growth modes. Furthermore, identification of their conductive structures has the possibility to make an important contribution 
to the development of bio-inspired electrically conductive materials.

\section{Biological nanotubes and related cell-to- cell connections}

Electrically conductive structures might not be the only strategy for transferring electrons between the interiors of adjacent cells. Desulfovibrio vulgaris and Clostridium acetobutylicum growing in co-culture in a sulfate-free glucose medium forged connections that permitted interspecies transfer of proteins and allowed $D$. vulgaris to grow even though sulfate was not available as an electron acceptor (Benomar et al., 2015). One possible explanation is that electron carriers, such as ferrodoxin, function as an interspecies electron shuttle (Figure 2): the shuttle is reduced within $D$. vulgaris; transferred to $C$. acetobutylicum via the intercellular connection; and oxidized with the reduction of organic electron acceptors or protons within C. acetobutylicum (Benomar et al., 2015). However, further study is required to verify this hypothesized novel method of interspecies electron exchange.

The connections between D. vulgaris and C. acetobutlyicum appeared to be a fusion of the two cells, but special nanotube structures are another strategy for interspecies exchange of cellular components (Dubey and Ben-Yehuda, 2011; Pande et al., 2015; Dubey et al., 2016). Membrane vesicles can also ferry a range of cellular components between cells (Hasegawa et al., 2015). Electron transport via diffusion of electron shuttles through nanotubes and related intercellular connections would be expected to be slower than electron transfer through electrically conductive structures shared between cells, as proposed for cable bacteria, but would be more selective and potentially faster than the release of an electron shuttle into the extracellular environment, such as in interspecies hydrogen transfer.

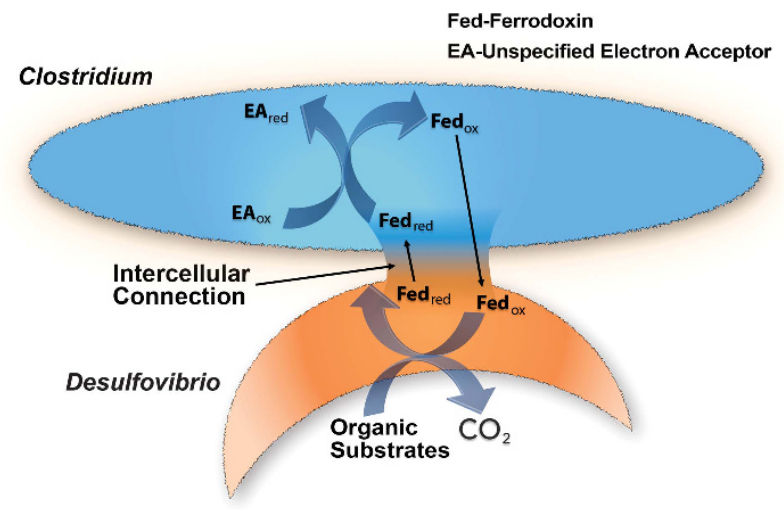

Figure 2 Model for electron exchange between Desulfovibrio vulgaris and Clostridium acetobutylicum proposed in Benomar et al., 2015. An electron shuttle, such as ferrodoxin, provides interspecies electron exchange by moving between the two species through an intercellular connection.
Shewanella oneidensis produces outer membrane extensions (Pirbadian et al., 2014) that look very similar to the nanotubes of other bacteria. It is often stated that the $S$. oneidensis outer membrane extensions form electrical connections between cells (Benomar et al., 2015; Blumberger, 2015; Shen et al., 2015), presumably because the $S$. oneidensis outer membrane extensions are referred to as microbial nanowires (Pirbadian et al., 2014). However, as previously reviewed (Lovley and Malvankar, 2015), there is no evidence that the $S$. oneidensis membrane extensions facilitate cell-to-cell electron transfer or any other form of long-range electron transport under physiologically relevant conditions.

The formation of nanotubes in Bacillus subtilis can be diminished by deleting the gene for YmdB, a phosphodiesterase (Dubey et al., 2016). Ymb is highly conserved in gram positive and gram negative bacteria (Dubey et al., 2016) and thus may provide a target for determining whether nanotubes are involved in extracellular electron exchange through gene deletion studies.

\section{Outer surface cytochrome matrix}

A conductive network of $C$-type cytochromes was proposed to support DIET in the consortia of methane-oxidizing ANME-2 archaea and sulfate reducers that have an important role in consuming methane in marine environments (McGlynn et al., 2015). It was speculated that the ANME-2/sulfate reducer aggregates were electrically conductive because estimates of microbial activity did not fit a model consistent with a diffusive interspecies electron carrier. Heme staining indicated the presence of $c$-type cytochromes not only in the membranes of ANME-2 and their sulfate-reducing partners, but also in the tight intercellular space between the cells (McGlynn et al., 2015). A model was suggested (Figure 3) in which ANME-2, which can oxidize methane with extracellular electron transfer (Scheller et al., 2016), transfer electrons to extracellular cytochromes that then form an electrical connection with outer surface cytochromes on the sulfate reducer, which can then transfer electrons into the cell for sulfate reduction (McGlynn et al., 2015). It was also proposed that the cytochromes provided a conductive matrix so that sulfate reducer cells not in close proximity to ANME-2 could receive electrons to support sulfate reduction. Major assumptions in this model have not yet been validated including: (1) whether the aggregates are electrically conductive; (2) whether cytochromes are sufficiently abundant to form a conductive matrix throughout the aggregates; and (3) whether the sulfate reducers are capable of using extracellularly derived electrons for sulfate reduction.

In evaluating this model, it is important to recognize that there is no instance in which a 


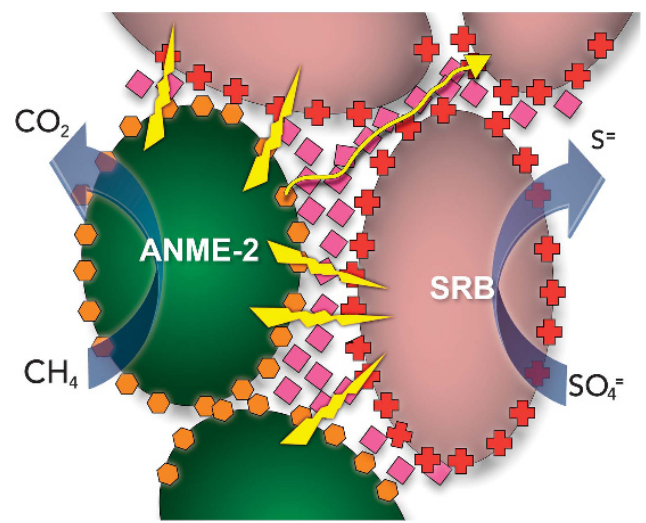

Figure 3 Model for direct interspecies electron transfer in consortium of ANME-2 (green) and syntrophic sulfate-reducing partner (pink) anaerobically oxidizing methane with the reduction of sulfate. Cytochrome (hexagons, diamonds and crosses)-based electron transfer proposed for adjacent cells (lightning bolts) and longer percolation path (yellow line) proposed for electron transfer to non-adjacent cells.

cytochrome-based biological conductive matrix capable of transporting electrons over $\mu \mathrm{m}$ distances has been verified. At one time it was thought that cytochrome-based electron exchange could account for the long-range electron transport through the conductive anode biofilms of Geobacter sulfurreducens microbial fuel cells (Strycharz et al., 2011b). However, subsequent studies demonstrated that, although cytochromes were highly abundant in the biofilms, the cytochrome density was not sufficient for cytochromes to make electrical connections over multiple cell lengths (Malvankar et al., 2012b). For example, the biofilms of a strain of $G$. sulfurreducens designed with poorly conductive pili have low conductivity despite the production of abundant $c$-type cytochromes (Vargas et al., 2013). Attempts to build artificial consortia that can perform DIET solely via cytochrome-to-cytochrome electron transfer with co-cultures of $G$. metallireducens and $G$. sulfurreducens have been unsuccessful, unless a soluble electron shuttle to mediate the extracellular electron transfer is also provided (Smith et al., 2015). Thus, the DIET model for the ANME-2 methaneoxidizing consortia is attractive, but there is as of yet little direct evidence to support the model.

\section{Networks of electrically conductive pili (e-pili)}

Conductive, multi-species aggregates participating in DIET are possible with networks of e-pili (Figure 4). This was first recognized when co-cultures of G. metallireducens and G. sulfurreducens were adaptively evolved to grow in a medium with ethanol as the electron donor and fumarate as the electron acceptor (Summers et al., 2010). G. metallireducens conserves energy to support growth by oxidizing ethanol to acetate with electron transfer to $G$. sulfurreducens, which can grow with electrons

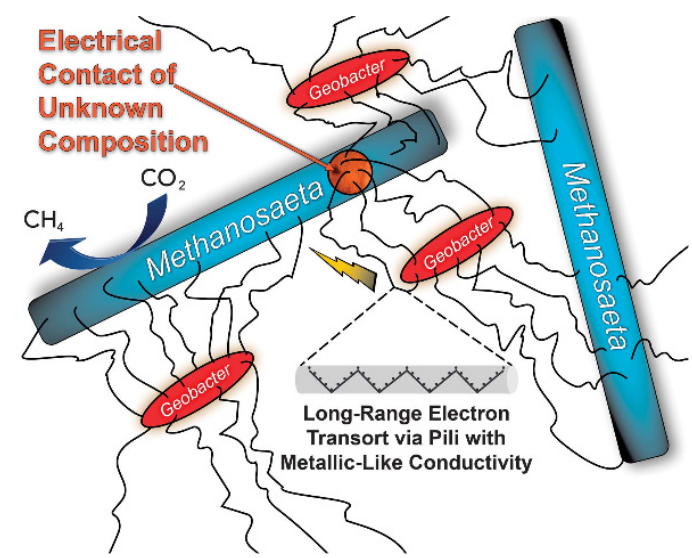

Figure 4 Model for direct interspecies electron transfer between Geobacter and Methanosaeta species. The gray tube illustrates the proposed metallic-like mechanism for conduction along the length of the e-pili via delocalized electrons associated with tightly packed aromatic amino acids.

solely derived from DIET (Shrestha et al., 2013a), but also consumes acetate released by $G$. metallireducens. As the co-culture adapted for syntrophic growth it formed large (1 $\mathrm{mm}$ diameter) electrically conductive aggregates that were filled with a dense network of e-pili (Summers et al., 2010). The two species were not uniformly distributed throughout the aggregates, suggesting that DIET does not require close interspecies associations for the interspecies electron exchange. Instead, it appears that the e-pili network within the aggregates forms a conductive matrix similar to that described in current-producing Geobacter biofilms (Reguera et al., 2006; Malvankar et al., 2011). As previously reviewed in detail (Malvankar and Lovley, 2014; Lovley and Malvankar, 2015), multiple lines of evidence suggest that the e-pili within Geobacter biofilms have a 'metallic-like' conductivity similar to that observed in synthetic organic conducting polymers (Malvankar et al., 2011), which can be attributed to closely packed aromatic amino acids that facilitate electron transport along the length of the pili (Vargas et al., 2013; Malvankar et al., 2014, 2015b; Adhikari et al., 2016; Xiao et al., 2016). There are alternative theoretical models for e-pili conductivity (see Feliciano et al., 2015 and Malvankar et al., 2015b for additional references and discussion), but the feasibility of DIET mediated by e-pili is not materially influenced by which model for electron transport along the length of the e-pili eventually prevails. The multi-heme $c$-type cytochrome OmcS, which is associated with e-pili (Leang et al., 2010), is important for DIET and is hypothesized to serve as an electrical contact to promote electron transfer to and from the pili (Summers et al., 2010). Diverse experimental approaches have supported this DIET model and have ruled out alternative models such as interspecies electron transfer via hydrogen or other electron shuttles (Summers et al., 2010; Rotaru et al., 2012; Shrestha et al., 2013a,b). 
The first environment in which DIET supported by e-pili was detected was anaerobic digesters converting brewery wastes to methane (Morita et al., 2011; Shrestha et al., 2014; Rotaru et al., 2014b). These upflow anaerobic sludge blanket digesters treat a relatively simple waste in which ethanol is a major constituent (Shrestha et al., 2014). Methanosaeta species were the dominant methanogens and Geobacter species were the most abundant and most metabolically active bacteria (Morita et al., 2011; Rotaru et al., 2014b). Metatranscriptomics revealed that the Methanosaeta species in the digester were highly expressing genes for the reduction of carbon dioxide to methane (Rotaru et al., 2014b), a surprising finding because Methanosaeta were not known to produce methane from carbon dioxide and do not use hydrogen or formate, typical electron donors for carbon dioxide reduction (Smith and Ingram-Smith, 2007). Defined co-culture studies with G. metallireducens and the digester isolate Methanosaeta harundinacea demonstrated that $M$. harundinacea could reduce carbon dioxide to methane with electrons received from $G$. metallireducens via DIET (Rotaru et al., 2014b). The conductivity of the digester aggregates and genetic studies with the defined co-culture demonstrated the importance of e-pili for DIET (Morita et al., 2011; Shrestha et al., 2014; Rotaru et al., 2014b).

The electrical contact(s) for Methanosaeta to accept electrons via DIET are unknown. However, Methanosarcina barkeri, which is closely related to Methanosaeta species and is genetically tractable, can also participate in DIET (Rotaru et al., 2014a; Wang et al., 2016) and thus may represent the best model organism for elucidating mechanisms for extracellular electron exchange in methanogens involved in DIET.

The ability of Methanosaeta to participate in DIET has potential importance in the global carbon cycle because of the abundance of Methanosaeta in terrestrial wetlands and aquatic sediments that significantly contribute to atmospheric methane (Smith and Ingram-Smith, 2007). For example, metatranscriptomic analysis of methanogenic rice paddy sediments revealed that Methanosaeta were highly expressing genes for carbon dioxide reduction and that there was also high expression of genes for e-pili by abundant Geobacter species (DE Holmes, personal communication). Expression of genes for carbon dioxide reduction in Methanosaeta was also noted in incubations of arctic peat soils (Tveit et al., 2015). Furthermore, Geobacter species were among the most metabolically active bacteria in Fe(III)depleted methanogenic rice paddy soils (Hori et al., 2007; Kim and Liesack, 2015), consistent with the concept that the Geobacter might be growing as syntrophic partners with methanogens.

DIET between bacteria and archaea partners facilitated by e-pili was also proposed for a thermophilic enrichment culture dominated by a methaneoxidizing archaeon in the ANME-1 phylogenetic clade and its electron-accepting partner, the hydrogenotrophic, sulfate reducer previously referred to as hot-seep-1 and now known as Candidatus Desulfofervidus auxilii (Wegener et al., 2015; Krukenberg et al., 2016). Even though the sulfate reducer effectively uses hydrogen as an electron donor, slow rates of hydrogen production by the consortium and a lack of hydrogenase gene sequences in the ANME-1 genome suggested that hydrogen was not the interspecies electron carrier (Wegener et al., 2015). Both partners greatly increased expression of genes for outer surface $c$-type cytochromes when cooperating to oxidize methane. Furthermore, the sulfate reducer also highly expressed genes for type IV pili when grown syntrophically, but not when grown on hydrogen (Wegener et al., 2015). Abundant pili were apparent with transmission electron microscopy in aggregates oxidizing methane (Wegener et al., 2015). The conductivity of the pili or the aggregates was not measured, but it was speculated that the pili might be electrically conductive in a manner similar to Geobacter e-pili (Wegener et al., 2015).

Other types of electrically conductive filaments have been documented and could potentially serve as electrical contacts for DIET. For example, the Fe (III)-reducing microorganism Aeromonas hydrophila (Castro et al., 2013), the Fe(II) oxidizer Acidothiobacillus ferroxidans ( $\mathrm{Li}$ and $\mathrm{Li}, 2014$ ) and the sulfate reducer D. desulfuricans (Eaktasang et al., 2016) produce filaments distinct from the Geobacter e-pili that are conductive across their diameter. Rhodopseudmonas palustris, specifically expresses electrically conductive filaments of unknown composition under $\mathrm{Fe}(\mathrm{III})$-reducing conditions (Venkidusamy et al., 2015). It does not appear that the ability of any of these organisms to exchange electrons with other species has been investigated yet. There is a wide diversity of other filaments in the microbial world that might be conductive and warrant investigation.

\section{DIET mediated by abiological conductive materials}

The need for conductive filaments for DIET can be alleviated with abiotic conductive materials (Figure 5). Conductive carbon materials such as granular activated carbon (Liu et al., 2012), biochar (Chen et al., 2014b) and carbon cloth (Chen et al., 2014a) all effectively wire different species together for DIET. Cells of both species attach to the conductive material, but are often not in close physical contact with other cells (Chen et al., 2014a, b; Liu et al., 2012). In the presence of conductive materials, it is possible to initiate cocultures of $G$. metallireducens/G. sulfurreducens or G. metallireducens/M. barkeri with Geobacter strains that lack the ability to produce either e-pili or the e-pili cytochrome OmcS (Chen et al., 2014a, b; Liu et al., 2012; Rotaru et al., 2014a). These results 


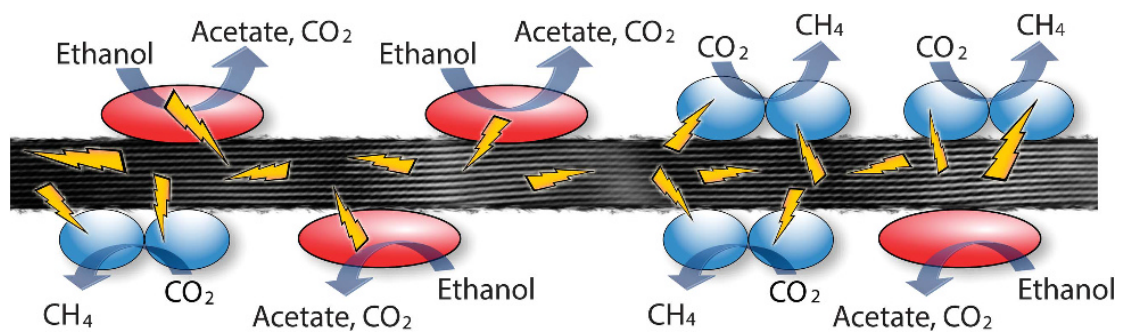

Figure 5 Model for electron exchange between Geobacter and Methanosarcina species mediated by carbon cloth. Lightning bolts depict electron transfer from Geobacter (red rods) through the cloth and to Methanosarcina (blue coccoids).

suggest that electron transport carriers associated with the outer surface of the cell are able to make the required electrical contacts with the conductive material.

The conductive iron mineral magnetite also promotes DIET (Kato et al., 2012a, b). The magnetite, which is typically smaller than the cells, has been observed to attach to the cells participating in DIET. Illustrations of magnetite-enhanced DIET often show chains of magnetite bridging between the electrondonating and the electron-accepting partner, but direct experimental evidence for this appears to be lacking. Genetic analysis of $G$. metallireducens $/ G$. sulfurreducens co-cultures and visualization of magnetite suggested that magnetite promoted DIET by attaching to e-pili, functioning as a surrogate for the e-pili cytochrome OmcS (Liu et al., 2015). In the presence of magnetite, a strain of $G$. sulfurreducens in which the gene for OmcS had been deleted was nearly as effective in DIET as the wild-type strain and wild-type cells downregulated expression of the $O \mathrm{mcS}_{\mathrm{S}}$ gene, presumably conserving energy when an OmcS substitute was available (Liu et al., 2015).

\section{Harnessing cell-to-cell electrical connections for practical applications}

Many technologies in which microbes interact with electrodes as either an electron acceptor or an electron donor are in development (Lovley and Nevin, 2013; Rosenbaum and Franks, 2014). The current-producing capabilities of Geobacter species were linked to their ability to participate in DIET, not their effectiveness in Fe(III) oxide reduction, suggesting that understanding DIET mechanisms may aid in promoting strategies for enhancing microbe-electrode interactions (Rotaru et al., 2015). e-pili, and possibly other electrically conductive components of e-communities, may be sources of sustainably produced electronic materials (Malvankar et al., 2012a; Adhikari et al., 2016; Tan et al., 2016).

Promoting DIET might enhance the anaerobic digestion of organic wastes, one of the few proven, effective, large-scale bioenergy strategies. Many studies have now shown that adding materials known to facilitate DIET either to anaerobic digesters, or methanogenic enrichment cultures metabolizing important intermediates in anaerobic digestion, can accelerate the rate of methane production; increase the methane content of the gas produced; and/or stabilize the digestion to permit higher organic loading rates (Viggi et al., 2014; Baek et al., 2015; Li et al., 2015a, b; Xu et al., 2015; Yamada et al., 2015; Zhao et al., 2015; Zhuang et al., 2015a, b; Beckmann et al., 2016; Lee et al., 2016). None of these studies have directly demonstrated DIET with detailed studies of microbial metabolism, but DIET was inferred from enrichment of microorganisms known to participate in DIET and/or increased rates of methane production. Genera of methanogens that are known to use $\mathrm{H}_{2}$ as an electron donor are abundant in anaerobic digesters treating complex organic wastes such as sewage sludge, manure, industrial waste and food waste (Regueiro et al., 2012; Vanwonterghem et al., 2014; Cai et al., 2016; Luo et al., 2016). The available evidence suggests that many of these methanogens are unlikely to participate in DIET (Rotaru et al., 2014b). These findings raise two important questions: (1) is DIET ever an important mechanism of electron exchange during the degradation of these complex wastes; and (2) will promoting DIET with the addition of conductive materials have a significant long-term impact on the performance of such digesters.

\section{Outlook}

The study of e-communities is clearly in its infancy, but their potential importance in biogeochemical cycles, as well as in practical applications such as bioenergy, is readily becoming apparent. With an increasing understanding of the mechanisms involved in DIET it will become easier to recognize e-communities in diverse environments. For example, based on the microorganisms present, it was inferred (Shrestha and Rotaru, 2014) that conversion of coal to methane (Jones et al., 2010) was carried out by a DIET-based community. As discussed above, the expression of key genes associated with DIET in Methanosaeta and Geobacter species has suggested that DIET is important in some rice paddy soils and as other electrical connectors are identified, it should be possible to more confidently identify additional e-communities from meta-omics data. 
Studies to date have focused on microbial communities in which one primary substrate (ethanol, methane) is fueling most of the microbial activity and DIET is essential for metabolism of that substrate. Additional substrates known to be metabolized via DIET are, so far, restricted to simple alcohols and short-chain fatty acids (Wang et al., 2016). Thus, in more complex environments DIET may be just one of multiple types of interspecies interactions and detecting DIET will be more technically difficult.

As more information becomes available to advance the modeling of e-communities (Nagarajan et al., 2013; Storck et al., 2015), it will become more feasible to predict which conditions favor direct electrical connections over electron exchange via hydrogen or other shuttles. e-communities are analogous to the electrification of human civilization. Rapid transportation of energy via electrons through the grid has greatly improved the quality of human life, but in some instances economic or technical considerations still favor the slower conveyance of energy between providers and consumers in the form of chemical bonds (wood, coal and petroleum). The same must be true for microbial communities-the abundance of microorganisms that function via interspecies hydrogen transfer demonstrates that speed of electron transfer is not always the only consideration in choosing a route to share energy.

The emergence of many studies engineering DIET with conductive materials is one example of how a functional understanding can facilitate directing e-communities toward better performance. On the horizon may be construction of synthetic e-communities. There are a diversity of materials such as redox-active polymers, inorganic nanoparticles, carbon nanotubes and graphene that improve the ability of some microorganisms to electrochemically interact with their extracellular environment, especially when those microorganisms lack an inherent effective capacity for extracellular electron exchange (Ajo-Franklin and Noy, 2015; Du et al., 2014). Electrification of designer microbial communities may make processes less susceptible to contamination with competing microorganisms than synthetic communities that rely on shared metabolites for metabolic cooperation.

Just as the electrification of human civilization for energy exchange was followed by the internet for information exchange, it may be that microbial communities can share information as well as energy through their electrical connections. This suggestion (Reguera, 2011) has yet to be experimentally verified, but it has already been demonstrated that electrical communication within biofilms is possible through ion channels (Masi et al., 2015; Prindle et al., 2015). Thus, electrical communication via electron exchange seems feasible. Whether or not this is an important phenomenon in natural communities, there is certainly the possibility of artificially controlling the activity of e-communities with electrical inputs that are already known to influence gene expression (Strycharz et al., 2011a).

Another intriguing concept is the possibility that microorganisms in the human gut may electrically interact with cells in the gut epithelium (Ericsson et al., 2015). This, and the strong possibility of microbe-microbe electrical communication in this anaerobic environment, suggests that the human gut may be one of the next exciting frontiers in the study of e-communities. Furthermore, there is a growing appreciation of the possibility that electrical communication via conductive protein filaments has an important role in the function and development of humans (Friesen et al., 2015). Electrically conductive microbial aggregates may provide a primitive model for better understanding the evolution and function of these larger multi-cellular electrical systems.

\section{Conflict of Interest}

The author declares no conflict of interest.

\section{Acknowledgements}

I would like to thank the many past and present members of my laboratory who have substantially contributed to the developing and understanding of e-communities including Zarath Summers, Nikhil Malvankar, Amelia Rotaru, Pravin Shrestha, Fanghua Liu, Shanshan Chen, Masahito Morita, Ashley Franks, Li-Ying Wang, Ramesh Adhikari, Dawn Holmes, Gemma Reguera and Kelly Nevin. The helpful comments of the manuscript referees are greatly appreciated. The Office of Naval Research Grants N00014-13-10549 and No00141-13-1-0550 supported this research.

\section{References}

Adhikari RY, Malvankar NS, Tuominen MT, Lovley DR. (2016). Conductivity of individual Geobacter pili. RSC Adv 6: 8354-8357.

Ajo-Franklin CM, Noy A. (2015). Crossing over: nanostructures that move electrons and ions across cellular membranes. Adv Mater 27: 5707-5804.

Baek G, Kim J, Cho K, Bae H, Lee C. (2015). The biostimulation of anaerobic digestion with (semi) conductive ferric oxides: their potential for enhanced biomethanation. Appl Microbiol Biotechnol 99: 10355-10366.

Beckmann S, Welte C, Li X, Oo YM, Kroeninger L, Heo Y et al. (2016). Novel phenazine crystals enable direct electron transfer to methanogens in anaerobic digestion by redox potential modulation. Energy Environ Sci 9: $644-655$.

Benomar S, Ranava D, Cardenas ML, Trably E, Rafrafi Y, Ducret A et al. (2015). Nutritional stress induces exchange of cell material and energetic coupling between bacterial species. Nat Commun 6: 6283.

Blumberger J. (2015). Recent advances in the theory and molecular simulation of biological electron transfer reactions. Chem Rev 115: 11191-11238. 
Cai M, Wilkins D, Chen J, Ng S-K, Lu H, Jia Y et al. (2016). Key anaerobic digestion pathways in municipal sludge and industrial wastewater biogas-producing systems. Front Microbiol 7: 778.

Castro L, Vera M, Muñoz JA, Blázquez ML, González F, Sand $\mathrm{W}$ et al. (2013). Conductive filaments produced by Aeromonas hydrophila. Adv Mater Res 825: 210-213.

Chen S, Rotaru A-E, Liu F, Philips J, Woodard TL, Nevin $\mathrm{KP}$ et al. (2014a). Carbon cloth stimulates direct interspecies electron transfer in syntrophic cocultures. Bioresour Techol 173: 82-86.

Chen S, Rotaru A-E, Shrestha PM, Malvankar NS, Liu F, Fan W et al. (2014b). Promoting interspecies electron transfer with biochar. Sci Rep 4: 5019.

Du J, Catania C, Bazan GC. (2014). Modification of abiotic biotic interfaces with small molecules and nanomaterials for improved bioelectronics. Chem Mater 26: 686-697.

Dubey GP, Ben-Yehuda S. (2011). Intercellular nanotubes mediate bacterial communication. Cell 144: 590-600.

Dubey GP, Mohan GBM, Dubrovsky A, Amen T, Tsipshtein S, Rouvinski A et al. (2016). Architecture and characteristics of bacterial nanotubes. Dev Cell 36: 453-461.

Dyksam S, Bischof K, Fuchs BM, Hoffmann K, Meier D, Meyerdierks A et al. (2016). Ubiquitous Gammaproteobacteria dominate dark carbon fixation in coastal sediments. ISME J 10: 1939-1953.

Eaktasang N, Kang CS, Lim H, Kwean OS, Cho S, Kim Y et al. (2016). Production of electrically-conductive nanoscale filaments by sulfate- reducing bacteria in the microbial fuel cell. Bioresour Techol 201: 61-67.

Ericsson AC, Davis DJ, Franklin CL, Hagan CE. (2015). Exoelectrogenic capacity of host microbiota predicts lymphocyte recruitment to the gut. Physiol Genomics 47: 243-252.

Feliciano GT, Steidl RJ, Reguera G. (2015). Structural and functional insights into the conductive pili of Geobacter sulfurreducens revealed in molecular dynamics simulations. Phys Chem Chem Phys 17: 22217-22226.

Friesen DE, Craddock TJA, Kalra AP, Tuszynski JA. (2015). Biological wires, communication systems, and implications for disease. Biosystems 127: 14-27.

Hasegawa Y, Futamata H, Tashiro Y. (2015). Complexities of cell-to-cell communication through membrane vesicles: implications for selective interaction of membrane vesicles with microbial cells. Front Microbiol 6: 633 .

Holmes DE, Dang Y, Walker DJF, Lovley DR. (2016). The electrically conductive pili of Geobacter species are a recently evolved feature for extracellular electron transfer. Microb Genom 2; doi:10.1099/mgen.0.000072.

Hori T, Noll M, Igarashi Y, Friedrich MW, Conrad R. (2007). Identification of acetate-assimilating microorganisms under methanogenic conditions in anoxic rice field soil by comparative stable isotope probing of RNA. Appl Environ Microbiol 73: 101-109.

Jones EJP, Voytek MA, Corum MD, Orem WH. (2010). Stimulation of methane generation from nonproductive coal by addition of nutrients or a microbial consortium. Appl Environ Microbiol 76: 7013-7022.

Kato S, Hashimoto K, Wantanabe K. (2012a). Microbial interspecies electron transfer via electric currents through conductive minerals. Proc Natl Acad Sci USA 109: 10042-10046.
Kato S, Hashimoto K, Watanabe K. (2012b). Methanogenesis facilitated by electric syntrophy via (semi)conductive iron-oxide minerals. Environ Microbiol 14: 1646-1654.

Kim Y, Liesack W. (2015). Differential assemblage of functional units in paddy soil microbiomes. PLoS One 10: e0122221.

Krukenberg V, Harding K, Richter M, Glockner FO, GruberVodicka HR, Adam B et al. (2016). Candidatus Desulfofervidus auxilii, a hydrogenotrophic sulfatereducing bacterium involved in the thermophilic anaerobic oxidation of methane. Environ Microbiol 18: 3073-3091.

Larsen S, Nielsen LP, Schramm A. (2014). Cable bacteria associated with long-distance electron transport in New England salt marsh sediment. Environ Microbiol Rep 7: 175-179.

Leang C, Qian X, Mester T, Lovley DR. (2010). Alignment of the $c$-type cytochrome OmcS along pili of Geobacter sulfurreducens. Appl Environ Microbiol 76: 4080-4084.

Lee J-L, Lee S-H, Park H-D. (2016). Enrichment of specific electro-active microorganisms and enhancement of methane production by adding granular activated carbon in anaerobic reactors. Bioresour Techol 205: 205-212.

Li H, Chang J, Liu P, Fu L, Ding D, Lu Y. (2015a). Direct interspecies electron transfer accelerates syntrophic oxidation of butyrate in paddy soil enrichments. Environ Microbiol 17: 1533-1547.

Li Y, Li H. (2014). Type IV pili of Acidithiobacillus ferrooxidans can transfer electrons from extracellular electron donors. J Basic Microbiol 54: 226-231.

Li L-L, Tong Z-H, Fang C-Y, Chu J, Yu H-Q. (2015b). Response of anaerobic granular sludge to single-wall carbon nanotube exposure. Water Res 70: 1-8.

Liu F, Rotaru A-E, Shrestha PM, Malvankar NS, Nevin KP, Lovley DR. (2012). Promoting direct interspecies electron transfer with activated carbon. Energy Environ Sci 5: 8982-8989.

Liu F, Rotaru A-E, Shrestha PM, Malvankar NS, Nevin KP, Lovley DR. (2015). Magnetite compensates for the lack of a pilin-assoicated c-type cytochrome in extracellular electron exchange. Environ Microbiol 17: 648-655.

Lovley DR. (2011). Reach out and touch someone: potential impact of DIET (direct interspecies energy transfer) on anaerobic biogeochemistry, bioremediation, and bioenergy. Rev Environ Sci Biotechnol 10: 101-105.

Lovley DR, Malvankar NS. (2015). Seeing is believing: novel imaging techniques help clarify microbial nanowire structure and function. Environ Microbiol 7: 2209-2215.

Lovley DR, Nevin KP. (2013). Electrobiocommodities: powering microbial production of fuels and commodity chemicals from carbon dioxide with electricity. Curr Opin Biotechnol 24: 385-390.

Luo G, Fotidis IA, Angelidaki I. (2016). Comparative analysis of taxonomic, functional, and metabolic patterns of microbiomes from 14 full-scale biogas reactors by metagenomic sequencing and radioisotopic analysis. Biotechnol Biofuels 9: 51.

Malkin SY, Meysman FJR. (2015). Rapid redox signal transmission by 'cable bacteria' beneath a photosynthetic biofilm. Appl Environ Microbiol 81: 948-956.

Malvankar N, Vargas M, Nevin KP, Franks AE, Leang C, Kim B-C et al. (2011). Tunable metallic-like 
conductivity in nanostructured biofilms comprised of microbial nanowires. Nat Nanotechnol 6: 573-579.

Malvankar NS, King GM, Lovley DR. (2015a). Centimeterlong electron transport in marine sediments via conductive minerals. ISME J 9: 527-531.

Malvankar NS, Lovley DR. (2014). Microbial nanowires for bioenergy applications. Curr Opin Biotechnol 27: 88-95.

Malvankar NS, Mester T, Tuominen MT, Lovley DR. (2012a). Supercapacitors based on c-type cytochromes using conductive nanostructured networks of living bacteria. Chemphyschem 13: 463-468.

Malvankar NS, Tuominen MT, Lovley DR. (2012b). Lack of involvement of c-type cytochromes in long-range electron transport in microbial biofilms and nanowires. Energy Environ Sci 5: 8651-8659.

Malvankar NS, Vargas M, Nevin KP, Tremblay P-L, EvansLutterodt K, Nykypanchuk D et al. (2015b). Structural basis for metallic-like conductivity in microbial nanowires. MBio 6: e00084-e00015.

Malvankar NS, Yalcin SE, Tuominen MT, Lovley DR. (2014). Visualization of charge propagation along individual pili proteins using ambient electrostatic force microscopy. Nat Nanotechnol 9: 1012-1017.

Marzocchi U, Trojan D, Larsen S, Meyer RL, Revsbech NP, Schramm A et al. (2014). Electric coupling between distant nitrate reduction and sulfide oxidation in marine sediment. ISME J 8: 1682-1690.

Masi E, Ciszak M, Santopolo L, Frascella A, Giovannetti L, Marchi E et al. (2015). Electrical spiking in bacterial biofilms. J R Soc Interface 12: 20141036.

McGlynn SE, Chadwick GL, Kempes CP, Orphan VJ. (2015). Single cell activity reveals direct electron transfer in methanotrophic consortia. Nature 526: 531-535.

Morita M, Malvankar NS, Franks AE, Summers ZM, Giloteaux L, Rotaru AE et al. (2011). Potential for direct interspecies electron transfer in methanogenic wastewater digester aggregates. MBio 2: e00159-00111.

Nagarajan H, Embree M, Rotaru A-E, Shrestha PM, Feist AM, Palsson BO et al. (2013). Multi-omic characterization and modeling of interspecies electron transfer mechanisms and microbial community dynamics of syntrophic associations. Nat Commun 4: 2809.

Nielsen LP, Risgaard-Petersen N. (2015). Rethinking sediment biogeochemistry after the discovery of electric currents. Ann Rev Mar Sci 7: 424-442.

Pande S, Shitut S, Freund L, Westermann M, Bertels F, Colesie C et al. (2015). Metabolic cross-feeding via intercellular nanotubes among bacteria. Nat Commun 6: 6238.

Pfeffer C, Larsen S, Song J, Dong M, Besenbacher F, Meyer RL et al. (2012). Filamentous bacteria transport electrons over centimetre distances. Nature 491: 218221.

Phelan VV, Liu W-T, Pogliano K, Dorrestein PC. (2012). Microbial metabolic exchange-the chemotype-tophenotype link. Nature Chem Biol 8: 26-35.

Pirbadian S, Barchinger SE, Leung KM, Byun HS, Jangir Y, Bouhenni RA et al. (2014). Shewanella oneidensis MR-1 nanowires are outer membrane and periplasmic extensions of the extracellular electron transport components. Proc Natl Acad Sci USA 111: 12883-12888.

Ponomarova O, Patil KR. (2015). Metabolic interactions in microbial communities: untangling the Gordian knot. Curr Opin Microbiol 27: 37-44.
Prindle A, Liu J, Asally M, Ly S, Garcia-Ojalvo J, Süel GM. (2015). Ion channels enable electrical communication in bacterial communities. Nature 527: 59-64.

Regueiro L, Veiga P, Figueroa M, Alonso-Gutierrez J, Stams AJM, Lema JM et al. (2012). Relationship between microbial activity and microbial community structure in six full-scale anaerobic digesters. Microbiol Res 167: $581-589$.

Reguera G. (2011). When microbial conversations get physical. Trends Microbiol 19: 105-113.

Reguera G, Nevin KP, Nicoll JS, Covalla SF, Woodard TL, Lovley DR. (2006). Biofilm and nanowire production leads to increased current in Geobacter sulfurreducens fuel cells. Appl Environ Microbiol 72: 7345-7348.

Risgaard-Petersen N, Damgaard LR, Revil A, Nielsen LP. (2014). Mapping electron sources and sinks in a marine biogeobattery. J Geophys Res Biogeosci 119: 1475-1486.

Risgaard-Petersen N, Kristiansen M, Frederiksen RB, Dittmer AL, Bjerg JT, Trojan D et al. (2015). Cable bacteria in freshwater sediments. Appl Environ Microbiol 81: 6003-6011.

Rissgaard-Petersen N, Revil A, Meister P, Nielsen LP. (2012). Sulfur, iron-, and calcium cycling associated with natural electric currents running through marine sediment. Geochim Cosmochim Acta 92: 1-13.

Rosenbaum MA, Franks AE. (2014). Microbial catalysis in bioelectrochemical technologies: status quo, challenges and perspectives. Appl Microbiol Biotechnol 98: $509-518$.

Rotaru A-E, Shrestha PM, Liu A, Ueki T, Nevin KP, Lovley DR. (2012). Interspecies electron transfer via H2 and formate rather than direct electrical connections in co-cultures of Pelobacter carbinolicus and Geobacter sulfurreducens. Appl Environ Microbiol 78: 7645-7651.

Rotaru A-E, Shrestha PM, Liu F, Nevin KP, Lovley DR. (2014a). Direct interspecies electron transfer during syntrophic growth of Geobacter metallireducens and Methanosarcina barkeri on ethanol. Appl Environ Microbiol 80: 4599-4605.

Rotaru A-E, Shrestha PM, Liu F, Shrestha M, Shrestha D, Embree M et al. (2014b). A new model for electron flow during anaerobic digestion: direct interspecies electron transfer to Methanosaeta for the reduction of carbon dioxide to methane. Energy Environ Sci 7: 408-415.

Rotaru A-E, Woodard TL, Nevin KP, Lovley DR. (2015). Link between capacity for current production and syntrophic growth in Geobacter species. Front Microbiol 6: 744 .

Schauer R, Risgaard-Petersen N, Kjeldsen KU, Bjerg JJT, Jørgensen BB, Schramm A et al. (2014). Succession of cable bacteria and electric currents in marine sediment. ISME J 8: 1314-1322.

Scheller S, Yu H, Chadwick GL, McGlynn SE, Orphan VJ. (2016). Artificial electron acceptors decouple archaeal methane oxidation from sulfate reduction. Science 351: 703-707.

Shen L, Zhao Q, Wu X, Li X, Li Q, Wang Y. (2015). Interspecies electron transfer in syntrophic methanogenic consortia: from cultures to bioreactors. Renew Sustainable Energy Rev 54: 1358-1367.

Shrestha PM, Malvankar NS, Werner JJ, Franks AE, Rotaru A-E, Shrestha M et al. (2014). Correlation between microbial community and granule conductivity in anaerobic bioreactors for brewery wastewater treatment. Bioresour Techol 174: 306-310. 
Shrestha PM, Rotaru A-E. (2014). Plugging in or going wireless: strategies for interspecies electron transfer. Front Microbiol 5: 237.

Shrestha PM, Rotaru A-E, Aklujkar M, Liu F, Shrestha M, Summers ZM et al. (2013a). Syntrophic growth with direct interspecies electron transfer as the primary mechanism for energy exchange. Environ Microbiol Rep 5: 904-910.

Shrestha PM, Rotaru A-E, Summers ZM, Shrestha M, Liu F, Lovley DR. (2013b). Transcriptomic and genetic analysis of direct interspecies electron transfer. Appl Environ Microbiol 79: 2397-2404.

Sieber JR, McInerney MJ, Gunsalus RP. (2012). Genomic insights into syntrophy: the paradigm for anaerobic metabolic cooperation. Ann Rev Microbiol 66: 429-452.

Smith JA, Nevin KP, Lovley DR. (2015). Syntrophic growth via quinone-mediated interspecies electron transfer. Front Microbiol 6: 121.

Smith KS, Ingram-Smith C. (2007). Methanosaeta, the forgotten methanogen? Trends Microbiol 15: 150-155.

Stams AJ, Plugge CM. (2009). Electron transfer in syntrophic communities of anaerobic bacteria and archaea. Nat Rev Microbiol 7: 568-577.

Storck T, Virdis B, Batstone DJ. (2015). Modelling extracellular limitations for mediated versus direct interspecies electron transfer. ISME J 10: 621-631.

Strycharz SM, Glaven RH, Coppi MV, Gannon SM, Perpetua LA, Liu A et al. (2011a). Gene expression and deletion analysis of mechanisms for electron transfer from electrodes to Geobacter sulfurreducens. Bioelectrochemistry 80: 142-150.

Strycharz SM, Malanoski AP, Snider RM, Yi H, Lovley DR, Tender LM (2011b). Application of cyclic voltammetry to investigate enhanced catalytic current generation by biofilm-modified anodes of Geobacter sulfurreducens strain DL1 vs variant strain KN400. Energy Environ Sci 4: 896-913.

Summers ZM, Fogarty H, Leang C, Franks AE, Malvankar NS, Lovley DR. (2010). Direct exchange of electrons within aggregates of an evolved syntrophic co-culture of anaerobic bacteria. Science 330: 1413-1415.

Tan Y, Adhikari RY, Malvankar NS, Pi S, Ward JE, Woodard TL et al. (2016). Synthetic biological protein nanowires with high conductivity. Small 12: 44814485.

Tveit AT, Urich T, Frenzel P, Svenning MM. (2015). Metabolic and trophic interactions modulate methane production by Arctic peat microbiota in response to warming. Proc Natl Acad Sci USA 112: E2507-E2516.

Vanwonterghem I, Jensen PD, Ho DP, Batstone DJ, Tyson GW. (2014). Linking microbial community structure, interactions and function in anaerobic digesters using new molecular techniques. Curr Opin Biotechnol 27: 55-64.
Vargas M, Malvankar NS, Tremblay P-L, Leang C, Smith JA, Patel P et al. (2013). Aromatic amino acids required for pili conductivity and long-range extracellular electron transport in Geobacter sulfurreducens. MBio 4: e00105-e00113.

Vasquez-Cardenas D, van de Vossenberg J, Polerecky L, Malkin SY, Schauer R, Hidalgo-Martinez S et al. (2015). Microbial carbon metabolism associated with electrogenic sulphur oxidation in coastal sediments. ISME J 9: 1966-1978.

Venkidusamy K, Megharah M, Schroder U, Karouta F, Mohan SV, Naidu R. (2015). Electron transport through electrically conductive nanofilaments in Rhodopseudomonas palustris strain RP2. RSC Adv 5: 100790100798.

Viggi CC, Rossetti S, Fazi S, Paiano P, Majone M, Aulenta F. (2014). Magnetite particles triggering a faster and more robust syntrophic pathway of methanogenic propionate degradation. Environ Sci Tech 48: $7536-7543$.

Wang L-Y, Nevin KP, Woodard TL, Mu B-Z, Lovley DR. (2016). Expanding the diet for DIET: electron donors supporting direct interspecies electron transfer (DIET) in defined co-cultures. Front Microbiol 7: 236.

Wegener G, Krukenberg V, Riedel D, Tegetmeyer HE, Boetius A. (2015). Intercellular wiring enables electron transfer between methanotrophic archaea and bacteria. Nature 526: 587-590.

Xiao K, Malvankar NS, Shu C, Martz E, Lovley DR, Sun X. (2016). Low energy atomic models suggesting a pilus structure that could account for electrical conductivity along the length of Geobacter sulfurreducens pili. Sci Rep 6: 23385.

Xu S, He C, Luo L, Lu F, He P, Cui L. (2015). Comparing activated carbon of different particle sizes on enhancing methane generation in upflow anaerobic digester. Bioresour Techol 196: 606-612.

Yamada C, Kato S, Ueno Y, Ishii M, Igarashi Y. (2015). Conductive iron oxides accelerate thermophilic methanogenesis from acetate and propionate. J Biosci Bioeng 119: $678-682$.

Zhao Z, Zhang Y, Woodard TL, Nevin KP, Lovley DR. (2015). Enhancing syntrophic metabolism in up-flow anaerobic sludge blanket reactors with conductive carbon materials. Bioresour Techol 191: 140-145.

Zhuang L, Tang J, Wang Y, Hu M, Zhou S. (2015a). Conductive iron oxide minerals accelerate syntrophic cooperation in methanogenic benzoate degradation. J Hazard Mater 293: 37-45.

Zhuang L, Xu J, Tang J, Zhou S. (2015b). Effect of ferrihydrite biomineralization on methanogenesis in an anaerobic incubation from paddy soil. J Geophys Res Biogeosci 120: 876-886. 